\title{
El neopopulismo de la televisión chilena
}

Hace un par de años, con ocasión de los programas especiales hechos en la TV chilena, a raíz del Mundial de Fútbol realizado en Francia, se produjo un cierto alboroto público debido a las declaraciones de un diputado que acusó a la TV de chabacana y vulgar y, además, pidió la conformación de una comisión especial que estudiara el estado de la TV en nuestro país(1).

En realidad, con matices o énfasis distintos, durante los años '90 ha sido rutinario conocer una visión crítica y, en algunos casos, francamente condenatoria sobre la programación televisiva. En síntesis, dichos planteamientos es posible agruparlos en torno a las siguientes ideas:

1.- la TV chilena adolece de inteligencia, originalidad y creatividad. Se le adjudica ser torpe, burda y poco inteligente. El juicio anterior se condensa en la idea de ser un producto comunicacional de mala calidad. Más aún, en ocasiones se hace hincapié en que se estaría desperdiciando la posibilidad de un uso distinto.

2.- la TV chilena produciría efectos sociales de atontamiento global. En ese sentido, ha habido una verdadera competencia de adjetivos que van desde una cretinización colectiva hasta la infantilización de la audiencia.

3.- la TV chilena (y en especial Televisión Nacional) no estaría cumpliendo la función, al parecer considerada naturalmente constitutiva, de dignificar su audiencia, en la perspectiva de la formación de ciudadanos y de fomento del desarrollo cultural nacional. En ese sentido, se pone énfasis en que no se haría cargo de temas realmente importantes.

Por de pronto, es posible afirmar que si hay algo de lo cual adolece la crítica intelectual e ilustrada es precisamente de originalidad y creatividad. El tipo de argumentos acerca de la naturaleza de la TV y sus efectos sociales no hace sino reproducir una visión de ya larguísima data y a la cual respondió, por ejemplo, Umberto Eco hace ya tres décadas al señalar que, por sí sola, la TV no logra formar la manera de pensar de una generación y sospechar de que los receptores muchas veces leen la TV diversamente de cómo la leen quienes la hacen; o cómo la leen parte de quienes la consumen de otro modo y, sobre todo, de cómo la leen la totalidad de los intelectuales que la analizan(2).

Por su lado, y no tan paradojalmente, la TV de Libre Recepción no sólo no se defiende de estas críticas, sino que las incorpora y las difunde(3).

Seguimos así frente a un círculo vicioso largamente conocido y teóricamente agotado y estéril. El punto sería encontrar un terreno analítico que no sólo se distancie de la falsa alternativa que supone que sólo es posible un juicio condenatorio repetitivo, encapsulado, distante y cuasi metafísico o la aceptación naturalizada de la realidad televisiva, como una simple expresión epocal, al igual que se hace con el orden social, sus fines y sus supuestos(4).

En esa dirección, no aparece ocioso comenzar sosteniendo que, a estas alturas del debate y de las actuales realidades en el campo, resulta insostenible la pretensión de contar con una clave conceptual y/o metodológica capaz de dar cuenta de la televisión, omniabarcadora y totalizante. Más bien se trataría de concebir a la TV como un actor socio-cultural, situado históricamente y que asume cada vez más un aspecto multifacético y cambiante, producto entre otros factores de un acelerado y permanente proceso de cambios tecnológicos, sin olvidar además que su acción se sitúa en una compleja trama de interacciones y mediaciones socio-culturales, en las cuales se produce la construcción de imaginarios colectivos y de producción discursiva que se sedimenta como sentido común.

Dicho de otra forma, se trata de reconocer a la TV como un vasto y complejo territorio a recorrer, con múltiples entradas y con una variedad de enfoques y metodologías posibles de 
utilizar. Es decir, la pregunta que recorre esta mirada sería i qué problemas suscita la TV y cómo iluminarlos y ser iluminados por ellos?, sabiendo que se trata de formar un campo de observación, en el cual levantar, a su vez, un campo de preguntas que requieren ser exploradas tras un conocimiento que más que global o en perspectiva, es transversal.

\section{Televisión, mercado y consumo cultural}

En esa perspectiva, cabe constatar en una mirada superficial que efectivamente en los años '90 se ha desarrollado un sostenido proceso de lo que podríamos llamar plebeyización de la TV chilena. Desde la presencia creciente de un humor grueso, directo y sin mediaciones ni sutilezas hasta los personajes encarnados por Felipe Camiroaga o del Jappening con Ja, pasando el doble sentido más bien unívoco de que hace gala un Morandé o una reina de belleza, ambos de buena familia, por citar algunos ejemplos.

Insistimos, sin embargo, que los casos citados sólo constituyen manifestaciones puntuales de un proceso de alcance mucho mayor: la construcción de un discurso que, bajo la simulación de acatar la voluntad y los gustos del público, mima un cierto sentido común masivo, sedimentado en la perspectiva de los procesos de modernización actuales.

El escándalo que produce lo anterior en una crítica ilustrada dice relación con una supuesta traición a unos orígenes en que habría reinado una matriz iluminista y pedagógica en la TV chilena, construyendo la conocida visión nostálgica de la época de oro perdida. La impostura de dicha posición radica en que no se hace cargo de algunos hechos fundamentales: en primer lugar, de que la televisión universitaria y estatal de los '60 o principios de los '70 más bien era un híbrido, en el cual jugó un papel crecientemente importante la inversión publicitaria y, con ella, los elementos característicos de un modelo de televisión comercial(5).

Por otro lado, no se hace mención al proceso a través del cual ha ido evolucionando el carácter de la TV en Chile y el que, a su vez, dice relación con las transformaciones y características del desarrollo del campo cultural en general y más allá todavía del proceso modernizador actual, puesto en marcha por el régimen militar y que ha consagrado el papel del mercado como eje articulador del campo cultural y su lógica impregnando la casi totalidad de las prácticas y relaciones sociales.

Todos los estudios realizados en los años '90 sobre consumo cultural en nuestro país han señalado que, de lejos, los productos culturales que tienen un nivel realmente masivo de consumo son aquellos provenientes de la industria cultural, en especial de la TV y luego de la Radio. Más aún, en el caso de la TV la incorporación de tecnologías que han posibilitado la diversificación de la oferta televisiva en varios planos distintos, han contribuido a expandir aún más dicho mercado(6).

En ese marco y teniendo como motivación central la lucha entre canales por la inversión publicitaria, es que se produce la necesidad para ellos de establecer relaciones y complicidades estrechas con una mentalidad y un sentido común masivos. Todo ello acrecentado por el hecho de que la modernización instala a los canales nacionales en una competencia global, atendiendo a la variedad de ofertas televisivas universales, enfrentadas a una demanda que transita, vía zapping desde lo universal a lo particular y viceversa.

Avanzando en esa dirección, se puede sostener que la TV chilena (y por qué no la radio y la prensa escrita) realizan una compleja operación discursiva que les está permitiendo trasvestir el viejo populismo político del siglo XX, en una suerte de neo-populismo administrado desde y por el mercado.

\section{Populismo e industria cultural en América Latina}

Dicho fenómeno viene a remarcar una tendencia que, en una retrospectiva histórica, le permitió afirmar a Martín Barbero que, en América Latina, en el siglo XX, las masas se han modernizado mucho más por la industria cultural y los medios de comunicación ( cine, radio y 
TV, con distintos énfasis según los países), que por los libros, la escuela o la influencia ilustradora y civilizadora de la ciudad letrada, en el sentido que Angel Rama le dio a esta noción(7).

No sería extraño a ello el escaso interés existente entre los medios intelectuales, en especial en nuestro país, por estudiar lo que podríamos llamar populismo en la cultura, por oposición al espacio que se le ha destinado al populismo en tanto fenómeno político.

La afirmación anterior proviene de la instalación en los estudios sobre comunicación y medios de una nueva perspectiva:

"...que trata de superar la concepción puramente manipulatoria de la cultura, sin introducir la historia para pensar la relación entre masificación cultural y entrada de las masas en la política, consecución por las masas de su visibilidad social, con la ambigüedad política que las masas siempre tuvieron y que la izquierda quiso resolver designándolas como revolucionarias o fascistas, cuando la historia de la constitución de las masas es mucho más compleja y ambigua que lo que esas designaciones recortan, y ello tanto en el caso del populismo brasileño, como en el del populismo mexicano o argentino, para hablar de los populismos que tuvieron una dramatización más explícita"(8)

Por otra parte, el autor citado hace ver la incomodidad que ello le produjo históricamente a la elite culta e intelectual, e incluso política. En este último sentido, en muchos lugares de América Latina (por ejemplo, Argentina, México o Brasil) dicha incomodidad ante el ascenso de los procesos de masificación, y con ello de la visibilidad política y social de lo popular, en estrecha relación con el crecimiento y desarrollo de la industria cultural y los medios, habría descolocado a una izquierda incapaz de ver en esas masas más que enajenación e inmadurez política y social, dejándole el terreno libre al populismo clásico del siglo veinte, especialmente paradigmático en su manifestación histórica en dichos países ( J.D.Perón, PRI, G.Vargas).

Así, el populismo, sigue diciendo Martín Barbero, se constituyó en la forma de un Estado que decía fundar su legitimidad en la asunción de las aspiraciones populares y que, más que una estratagema desde el poder, resultó ser una organización del poder, que dio forma al compromiso entre masas y Estado. La formación de las masas urbanas, por otra parte, no sólo producía un aumento del conjunto de las clases populares, sino que la aparición de un nuevo modo de existencia de lo popular:

"Lo masivo es hibridación de lo nacional y lo extranjero, del patetismo popular y la preocupación burguesa por el ascenso, y de dos tipos básicos; los que sin ser ricos lo aparentan (...), y su más opuesto, los desgarrados tipos del suburbio y el hampa. Una cultura, en fin, esencialmente urbana, que corrige su marcado materialismo -lo que importa, lo que tiene valor es lo económico y lo que significa ascenso social-con el desborde de lo sentimental y lo pasional"

La interpelación a lo popular contuvo en el populismo elementos de clase (reivindicaciones salariales, derechos de organización, etc.), que eran dirigidos hacia una minoría de las masas populares y una interpelación nacional-popular que alcanzaba a la mayoría. La combinación de ambos posibilitó la eficacia de la apelación a las tradiciones populares y a la construcción de una cultura nacional. Y de ahí también, al decir de Martín Barbero, el rol peculiar de medios masivos que como el cine y la radio construían su discurso sobre la base de la continuidad del imaginario de masas con la memoria narrativa escénica e iconográfica popular en la propuesta de una imaginería y sensibilidad nacional.

Cabe poner de relieve que la realidad cultural mencionada se caracterizaba por la existencia de un espesor y densidad cultural, política e ideológica de base, que se articulaba con proyectos de modernización diversos y competitivos, vale decir, en un contexto donde la configuración del orden social, sus supuestos y fines no sólo estaban en discusión, sino que constituían lo medular del debate público. 


\section{Masas, pueblo y medios en Chile}

Es evidente que durante el siglo XX nuestro país no vivió una realidad similar en este ámbito a la de los países antes mencionados y, por ello, no conoció el fenómeno populista con esas dimensiones y profundidad, en tanto movimiento político de masas. Tal vez, ello se debió a la existencia de una Izquierda probablemente con una dosis mayor de sensibilidad cultural, a lo cual no puede ser ajeno el hecho de su origen más ligado a la dinámica de los movimientos sociales populares en constitución, que a esfuerzos de minorías ilustradas o directamente provenientes de ciclos inmigratorios masivos.

Si bien es materia de otro estudio, aún por hacer, cabe mencionar la compleja y, a veces, dramática trama de relaciones y conflictos entre esa dimensión específica y particular de la Izquierda chilena y su componente universalista proveniente de una matriz racionalista e ilustrada que, en general, fue hegemónica.

Para lo que nos interesa aquí basta con señalar que constituyó, en todo caso, un cierto cedazo que impidió su divorcio de las masas populares (como ocurrió en Argentina) y, con ello, impidió también la conformación de algún movimiento populista importante y duradero. Sin embargo, la complejidad del fenómeno significó que, de alguna manera, fuera también contaminada en sus proyectos ideológicos de algunas dosis de populismo(9).

Más allá y a pesar de eso, la industria cultural chilena durante el siglo XX generó diversos productos culturales, en variados formatos y géneros que podrían catalogarse de populistas. Así, por ejemplo, la prensa escrita ha constituido uno de los espacios comunicacionales donde dicha tendencia se mantiene desde fines del siglo XIX, es decir, desde los momentos en que, al calor del proceso de modernización liberal-oligárquico se comienzan a establecer las bases de una cultura y un mercado cultural de masas, en conjunto con el desarrollo en su interior de lo que, en otro lugar, hemos llamado esfera pública plebeya(10).

En referencia a lo anterior, es conocido y paradigmático el trabajo de Guillermo Sunkel acerca de ese tipo de prensa(11). A partir de la diferenciación de dos matrices culturales al interior de la cultura popular en nuestro país, en el siglo XX, la racional-iluminista y la simbólico-dramática, el citado autor da cuenta de un particular tipo de periódicos que recorren toda la centuria, en especial el diario Clarín (1954-1973) como verdadero caso paradigmático. Sunkel remarca la filiación de estos productos periodísticos con antecedentes del siglo XIX, como por ejemplo, la poesía popular, expresadas en las llamadas Liras Populares, de masiva circulación(12).

Sin embargo, dicha matriz no es exclusiva de la prensa. Por el contrario, dice relación con una estructura narrativa, como es el melodrama, que se encuentra en la música, el cine, el radioteatro o la telenovela(13). Efectivamente, en sus orígenes, la TV chilena estuvo aparentemente ajena a lo anterior y ello tal vez produce la ilusión, acrecentada con el paso del tiempo, de una programación regida por los parámetros de la alta cultura. Sin embargo, dicha visión olvida que el programa televisivo más importante de los primeros treinta años de la TV en nuestro país (Sábados Gigantes) perfectamente podría caracterizarse de populista, de acuerdo a lo planteado anteriormente(14).

\section{La TV: ¿conductor y servidor de las masas?}

Pero, con ello no estamos hablando de la realidad de los últimos años. Debilitados, por decir lo menos, o francamente desaparecidos dichos movimientos populistas clásicos, o los Estados nacional-desarrollistas o una Izquierda con fuertes proyectos ideológicos, la hipótesis a levantar es que todo ello generó un vacío ocupado por actores como la TV o la Radio, principalmente, que han encontrado las mejores condiciones para constituirse en los fundamentales referentes de construcción de imaginarios colectivos masivos, en torno a lo político, lo público y los procesos de modernización. 
En ese sentido, se puede sostener que el discurso de la TV chilena lleva a cabo una operación sistemática para crear efectos de sentido sobre la vida y cultura cotidiana, estableciendo una compleja relación con el sentido común, en un plano de interacciones y mutuas determinaciones.

Se trataría de una racionalidad no exterior a dicho sentido común, sino que parte de la misma visión de mundo hegemónica. A la vez, implica una puesta en texto, a partir de la operación de cierto lenguaje, como el audiovisual, el cual contiene en sí mismo una multiplicidad de códigos que tiene a la imagen como eje articulador, lo cual implica, a su vez, interpelar una sensibilidad y ciertos mecanismos de entender y comprender el mundo específicos, distintos a los de la cultura letrada. En ese sentido, el discurso televisivo no es discernible desde su pura inmanencia, sino desde la radical historicidad de toda estrategia comunicacional(15).

Lo anterior implica también que la comprensión y análisis de dicho rol de la TV en tanto actor socio-cultural, requiere necesariamente de dar cuenta de sus relaciones con hegemonías culturales, sociales, políticas y económicas más globales. En este período ello supone remarcar la importancia de la naturalización del orden y los fines sociales, a partir de la consagración de la economía de mercado y la democracia liberal como los únicos soportes posibles de cualquier ordenamiento social presente o futuro.

En ese marco, la TV chilena opera de manera significativa en la escritura y construcción cotidiana de la realidad nacional, semantizando su instalación en los procesos universales y globales de desarrollo del capitalismo actual. Todo ello de manera incluyente, globalizando lo particular y nacionalizando lo global, o como dicen algunos, glocalizando(16).

En esa perspectiva, la TV aparece como un espacio con ventajas comparativas frente a otros, predominantes en otras épocas, como el sistema de partidos, el aparato educacional o el propio Estado, para relacionarse directamente con los individuos, recoger sus demandas circunscritas a ámbitos específicos y particulares, difundirlas, generar debates en torno a ellas y, muchas veces, darles satisfacción.

Cabe remarcar también que lo anterior dice estrecha relación con el hecho de que el modelo modernizador instala al mercado como eje articulador de la mayor parte de las prácticas sociales. En ese sentido, es casi redundante descubrir ahora (como ya hace décadas lo hiciera Habermas) una superposición de los roles de ciudadano y consumidor. Más bien, podría ser más rentable analíticamente dar cuenta de los mecanismos actuales de constitución y funcionamiento de lo público y en él, del perfil y el rol del ciudadano actual(17).

De allí, la presencia cada vez mayor de la gente y sus problemas concretos como componentes de la parrilla programática y como enunciatario predilecto. En un estudio privado sobre Agenda Setting en la TV chilena se señala que, durante 1999 y en plena campaña electoral presidencial, en los noticieros centrales el $48 \%$ del espacio estuvo dedicado a las personas individuales planteando algún tipo de problema, demanda o drama particular.

Es decir, la TV operando como escenario de lo público, entendido éste como una suerte de prolongación o sumatoria de los problemas individuales, privados o particulares y, a la vez, ofreciéndose como instrumento de la gente para vehiculizar, difundir y satisfacer las demandas, no de actores o sujetos sociales, sino de diversos segmentos de audiencia. Este ciudadano actual, concentrado en sí mismo y en sus intereses particulares, se desplaza a lo social como en un acto segundo, cuando lo colectivo amenaza su pequeño mundo. De allí que aún cuando sea capaz de movilizarse social o políticamente, ello nunca tendrá lo global como horizonte(18).

Para ello, la TV cuenta con una extensa gama de formatos que le permiten incluso construir metatextualidades al interior de su malla programática, en torno a un problema o una demanda: programas de conversación, reality show, telenoticieros, reportajes especiales, programas matinales, etc. 
La TV se postula así como el gran defensor de los débiles frente a los distintos poderes (como aparece recurrentemente en los noticieros o programas periodísticos en general, en las quejas y denuncias de consumidores frente a las empresas, públicas o privadas), su representante, vocero, pero también orientador y guardián de una normatividad sobre los valores, el bien y el orden.

En este último sentido opera la sistematización de la vida cotidiana haciéndola sinónimo de modernización. Es decir, el proyecto modernizador naturalizado aparece reducido a una manera de estar en el mundo y en la época. Asimismo, la plebeyización del discurso televisivo va mucho más allá del uso de un lenguaje procaz o vulgar como escandaliza a algunos. Se trata de la cooptación, absolutamente necesaria y mecanismo común a los populismos, de costumbres, gustos, modos de habla e imaginarios que remiten a lo masivo y que se entroncan con raíces culturales populares, pero en esta época desprovistos o limpiados de todo sedimento identitario o clasista(19).

Entonces, no se trata como afirma Tironi de que la sociedad emergente de los '90(20) en nuestro país esté contemplando una suerte de proceso de masificación como expresión de la democratización profunda y del acceso de la gente común y corriente al poder económico, político o cultural, por la vía del acceso a todo tipo de bienes y servicios, sino de una nueva fase o versión del proceso modernizador caracterizado, por el contrario, por la segmentación y fraccionamiento de los colectivos sociales anteriores, a partir de intensos procesos de privatización e individuación, con lo que la TV actúa en el centro mismo de los complejos procesos que articulan lo que la teoría crítica clásica no fue capaz de preveer: la homogeneización y universalización complementaria de una profunda heterogeneización y localización cultural, ofrecidos al consumo como diversidad democrática.

Y lo anterior ligado estrechamente al proceso de desarrollo del populismo de mercado que tiene a los medios (y en especial a la TV) como actores fundamentales. Dichos procesos son los que han permitido la construcción de una suerte de base social de apoyo a las hegemonías actuales, que tendría la fisonomía de una mentalidad de clase media recién llegada a la modernidad y al consumo y con incrustaciones de fragmentos residuales, fuera de contexto histórico y social, de elementos de la cultura popular, desprovistos de toda referencialidad y convertidos en meros significantes.

1 Ver Informe Cámara de Diputados

2 Ver ECO, Umberto: ¿El público perjudica a la TV?, en MORAGAS, Miquel de : SOCIOLOGIA DE LA COMUNICACIÓN DE MASAS. Edit. G.Gili, Barcelona, 1982. También, WOLF, Mauro: LOS EFECTOS SOCIALES DE LOS MEDIA. Paidós, Barcelona, 1994 y VILCHES, Lorenzo: LA TELEVISION. Los efectos del bien y el mal. Paidós, Barcelona, 1993. Es obvio que en esta dirección cabe recordar especialmente los trabajos de los llamados Estudios Culturales. Al respecto, ver CURRAN, J.; MORLEY, D. Y Walkerdine, V. (Comp.) : ESTUDIOS CULTURALES Y COMUNICACIÓN. Paidós Comunicación, Barcelona, 1998.

3 Así por ejemplo, en un reciente programa de Informe Especial (TVN) sobre la delincuencia juvenil se señalaba cómo la fiebre del consumo que difundiría la TV era un factor que estimulaba al delito.

4 En este último sentido, ver TIRONI, Eugenio: LA IRRUPCION DE LAS MASAS Y EL MALESTAR DE LAS ELITES. Edit. Grijalbo, Stgo., 1999.

5 Ver HURTADO, María de la Luz: HISTORIA DE LA TV EN CHILE (1958-1973). Ediciones Documentas-CENECA, Stgo., 1989.

6 Al respecto, ver los estudios publicados tanto por el Consejo Nacional de Televisión como por la Secretaría de Comunicación y Cultura.

7 Ver MARTIN BARBERO, Jesús: DE LOS MEDIOS A LAS MEDIACIONES. Edit. G.Gili, México, 1986 y PRE-TEXTOS. Conversaciones sobre comunicación. Editorial Universidad del Valle, Cali, 1996. 
8 MARTIN BARBERO, Jesús: PRE-TEXTOS...Op. Cit. Pág. 31.

9 Ver por ejemplo, DRAKE, Paul: SOCIALISMO Y POPULISMO. Chile 1936-1973.Ediciones Universidad Católica de Valparaíso, Valparaíso, 1992. También, FAUNDEZ, Julio: IZQUIERDAS Y DEMOCRACIA EN CHILE. 1932-1973. Ediciones BAT, Stgo. 1992.

10 Ver OSSANDON B., Carlos y SANTA CRUZ A., Eduardo: DE LAS ALAS AL PLOMO. El origen de la prensa de masas en Chile. Ediciones ARCIS-LOM, Stgo. 2000. (Próximo a aparecer).

11 Ver SUNKEL, Guillermo: RAZÓN Y PASION EN LA PRENSA POPULAR. ILET, Stgo., 1995.

12 Ver URIBE E., Juan: TIPOS Y CUADROS DE COSTUMBRES EN LA POESIA POPULAR DEL SIGLO XIX. Pineda Libros, Stgo., 1973.

13 Ver MARTIN BARBERO, Jesús y MUÑOZ, Sonia: TELENOVELA Y MELODRAMA. Ediciones Universidad del Valle, Cali, 1992.14. Ver ALTAMIRANO, Juan Carlos: ASI, ASI SE MUEVE DON FRANCISCO, ILET, Stgo., 1989.

15 Dicho concepto lo hemos trabajado en textos anteriores. Ver por ejemplo: MODELOS Y ESTRATEGIAS DE PRENSA EN PROCESOS DE MODERNIZACION: Chile Siglo XX. Centro de Investigaciones Sociales, Universidad ARCIS. Documento de Trabajo $N^{\circ} 2$, Stgo., Julio 1996.

16 OSSA, Carlos J.: Televisión chilena: la reinstitucionalización de la vida cotidiana. Documento de circulación interna. Centro de Investigaciones Sociales, Universidad ARCIS, Santiago, Agosto 2000.

17 Ver GARCIA CANCLINI, Nestor: CONSUMIDORES Y CIUDADANOS. Edit. Grijalbo, México, 1995. En Chile y en una dirección distinta, ver MOULIAN, Tomás: CHILE ACTUAL. Anatomía de un mito. Ediciones ARCIS- LOM, Stgo., 1997 y EL CONSUMO ME CONSUME. LOM Editores, Stgo., 1998.

18 Ver SANTA CRUZ, A. Eduardo: La inefable clase media, en Revista IN-FRAGANTI N² 2, Julio 1999. Centro de Investigaciones Sociales, Universidad ARCIS.

19 Ver ALVARADO, Roxana: La prensa sensacionalista: el caso de La Cuarta. Documento de Trabajo № 20. Centro de Investigaciones Sociales, Universidad ARCIS, Stgo., Octubre 1997.

20 Es por lo menos curioso que utilice la misma denominación que usaran Joaquín Lavín y Luis Larraín para referirse a los resultados del modelo modernizador en los '80. Ver LAVIN, J. Y LARRAIN, L.: CHILE, SOCIEDAD EMERGENTE. Edit. Zigzag, Stgo., 1989, en el cual se afirma una mirada sobre los resultados del proyecto modernizador que no es tan distinta. 